\title{
América Central: Puente lingüístico de las Américas
}

\author{
Francisco Moreno Fernández \\ Universidad de Alcalá - Instituto Cervantes
}

La historia de la geografía lingüística del español está escrita con la pluma de un puñado de expertos, capaces de abanderar grandes proyectos de investigación lingüística y de legar nuevos conocimientos y métodos a las siguientes generaciones. En 1930, Tomás Navarro Tomás hizo suyo el Atlas Lingüístico de la Península Ibérica y lideró los trabajos que por primera vez reunieron muestras habladas del español, el catalán, el gallego y el portugués peninsulares. En 1952, Manuel Alvar inició el Atlas Lingüístico y Etnográfico de Andalucía, dando comienzo a la más impresionante serie de atlas lingüísticos regionales dirigida por un solo autor. Desde 1958 Luis Flórez coordinó los trabajos del Atlas Lingüístico y Etnográfico de Colombia, primer atlas nacional de Hispanoamérica concebido y culminado como tal. En 1980 se comenzó el cartografiado del monumental Atlas Lingüístico de México, capitaneado por Juan M. Lope Blanch. En 1984 se iniciaron las encuestas encaminadas a la elaboración del Atlas Lingüístico de Hispanoamérica, proyectado por Manuel Alvar y Antonio Quilis en los años setenta y que, a partir de 2000, empezaron a ver la luz en forma de una colección, dirigida también por Manuel Alvar, cuyo primer volumen fue El español en el Sur de los Estados Unidos (2000). Y el inicio del siglo XXI pudo ver cómo el nombre de Miguel Ángel Quesada Pacheco se unía al de sus eximios predecesores, cuando el Atlas lingüístico de América Central comenzó a tomar su forma definitiva.

Puede decirse sin errar que el español hablado en América Central ha sido un gran desconocido, en su conjunto, hasta prácticamente el cambio de siglo, lo que ha venido a revalorizar los encomiables estudios de David Canfield o de John Lipski, junto a los primeros informes de Antonio Quilis o los análisis regionales de profesores como Elsie Alvarado, Pedro Geoffroy o Atanasio Herranz. La carencia bibliográfica se ha hecho más grave por tratarse el territorio centroamericano de un espacio con una notable complejidad geolingüística y sociolingüística. Situadas entre las grandes variedades mexicanas y colombianas, portadoras de rasgos caribeños o conservadores, las hablas de América Central muestran los efectos de la convivencia del español con 
multitud de lenguas originarias, especialmente el maya y el nahuatl, de los agudos contrastes entre lo urbano y lo rural y del cruce de influencias provocado por las migraciones internas. Sin duda, América Central es el gran puente lingüístico de las Américas, porque pone en contacto el Caribe con Norteamérica y lo indígena con lo europeo o lo africano, un puente pavimentado con un abigarrado mosaico de lenguas sobre el que el español se esparce como el agua de la lluvia tropical.

La tarea de describir semejante hervidero lingüístico ha requerido el trabajo de un investigador de amplios conocimientos y de voluntad inquebrantable: Miguel Ángel Quesada. El profesor Quesada, desde las aulas de Costa Rica y, muy especialmente, desde la Universidad de Bergen, en Noruega, ha sabido articular en proyecto de investigación complejo y ambicioso, cuyos resultados han ido apareciendo en publicaciones individuales y colectivas, referidas a territorios nacionales o regionales, que han ido completando una colección de materiales y de informes sobre el español de América Central que no encuentra fácil parangón con el de otras áreas hispánicas americanas. De tal modo es así, que el español centroamericano está en disposición de ser de los mejor conocidos de cualquier latitud. Este conocimiento lingüístico se está alcanzando gracias a la concurrencia de dos factores que el profesor Quesada ha sabido conjugar de un modo magnífico. Por un lado, la adopción de una metodología dialectológica calificada como «pluridimensional» e integradora de aspectos geográficos y sociales ineludibles para una correcta interpretación de la realidad lingüística. Por otro lado, la formación de una pléyade de jóvenes investigadores que garantizan unos excelentes resultados científicos en el presente y los mejores augurios para la dialectología hispanoamericana de las próximas décadas.

Los especialistas en la realidad internacional del español nos congratulamos de poder contar con los materiales que ahora se publican sobre Belice, El Salvador, Honduras y Panamá, coordinados por el profesor Quesada y ejecutados con un rigor metodológico digno de encomio. Con toda seguridad, estos trabajos servirán de base para numerosas investigaciones en el futuro y de inspiración tanto para los lingüistas de los países hispanohablantes como para los hispanistas de otras muchas procedencias. 


\section{Bibliografía}

Alvar, M. 2000. El español en el Sur de los Estados Unidos. Alcalá de Henares: Universidad de Alcalá.

Alvar, M. \& A. Quilis. 1974. Atlas Lingüístico de Hispanoamérica. Cuestionario. Madrid: C.S.I.C.

Alvarado de Ricord, E. 1971. El español de Panamá. Estudio fonético y fonológico. Panamá: Editorial Universitaria.

Canfield, D. L. 1962. La pronunciación del español en América. Bogotá: Instituto Caro y Cuervo.

Flórez, L. (dir.). 1982-1983. Atlas Lingüístico y Etnográfico de Colombia. Santafé de Bogotá: Instituto Caro y Cuervo.

Geoffroy Rivas, P. 1978. La lengua salvadoreña. 2a. ed. San Salvador: Dirección de Publicaciones e Impresos del Ministerio de Educación.

Herranz, A. 1990. El español hablado en Honduras. Tegucigalpa: Guaymuras.

Lipski, J. M. 1994. Latin American Spanish. New York: Longman Linguistics Library.

Lope Blanch, J. M. (dir.). 1990. Atlas lingüístico de México. T. 1. Vol. 1. México: El Colegio de México- Fondo de Cultura Económica.

Navarro Tomás, T. 1962. Atlas Lingüístico de la Península Ibérica, I: Fonética. Madrid: CSIC. 